\title{
Narratives of Loss: Exploring Grief through Photography
}

\author{
Belén Jiménez-Alonso ${ }^{1}$ (D) and Ignacio Brescó de Luna $^{2}$ \\ ${ }^{1}$ Universitat Oberta de Catalunya, Estudis de Psicologia i Ciències de l'Educació, Ronda Poblenou, 156 \\ 08018 Barcelona, Spain \\ ${ }^{2}$ Aalborg University, Department of Communication and Psychology, Teglgaards plads 1, 9000 Aalborg, \\ Denmark
}

Grief is not an exclusively private and intrapsychic phenomenon but a dynamic process whereby the bereaved negotiates the meaning of the loss in a way that may challenge his/her personal self-narrative. Drawing on a social constructionist model of grief, this paper features a case study where we analyse narratives of mourning elicited through a personal photographic project. The visual-based narrative methodology used in our study (photo-production) not only allows for multi-modal forms of expression and communication in the study of grief, but it also serves as an aid for individuals to scaffold further meaning-making processes which cannot be conveyed through narrative alone. The paper concludes with an invitation to reflect on the use of photography as both a possible methodological tool to explore narratives of grief and a therapeutic tool for the construction of meanings and continuing bonds with the deceased.

Keywords: grief, self-narrative, continuing bonds, meaning-making, photographs, photo-production.

\section{Introduction}

In recent years, general models of grief based on stages have been giving way to theories that emphasise the multiple possible understandings and unique experiences of each individual after a loss. Rather than suggesting a linear model bound by a set of common timeframes indicating what should occur in each phase, recent theoretical frameworks focus on the active process of meaningmaking whereby each person reconstructs a world challenged by loss, while trying to recreate the ongoing emotional connection with the deceased, known as continuing bonds (Klass, Silverman, \& Nickman, 1996). Along these lines, the social constructionist model of grieving (Neimeyer, Klass \& Dennis, 2014) highlights "the characteristically human processes of narration as a form of meaning- 
making" (p. 487). From this perspective, grief is conceived as a "situated interpretive and communicative activity" (p. 486). Rather than a psychological state to be endured or a stage people have to go through, this definition entails an active and dynamic process dialogically negotiated with family members, friends and other social actors, like therapists, in specific cultural settings with dominant narratives on how people should grieve.

In line with this approach, some recent studies have combined verbal and visual data in order to produce a richer picture of the grieving experience (Thompson \& Neimeyer, 2014; Weiskittle \& Gramling, 2018). In particular, photographs have been used not only as a method allowing for multi-modal forms of expression and communication (Reavey, 2011) in the study of grief, but also as an aid for scaffolding further meaning-making processes which cannot be conveyed through verbal narrative alone. Along these lines, the present paper features a case study, consisting of a photographic project, aimed at exploring the participant's meaning-making effort to restore a certain coherence to a life story altered by loss. More specifically, we analyse narratives of mourning elicited through a personal photographic project carried out in an online university extension course. Run by the first author, this course required participants to carry out a practical activity -a photographic project accompanied by brief written notes - to reflect on the possible therapeutic effects of firstperson photography. The case study will be preceded by an introduction of Neimeyer's notion of selfnarratives (Neimeyer, Klass \& Dennis, 2004) and a brief state of the art on the current use of photography as a methodological and therapeutic tool. The visual-based narrative methodology (Reavey, 2011) used in our study will lead us to discuss the usefulness of a multi-model approach to the experience of grief and the consideration of photography as both a possible methodological and therapeutic tool for the construction - and study - of meanings after a loss.

\section{Narratives and Photography as Meaning-Making Tools in Grief Experiences}

\section{Narratives Following Death-Related Loss}

According to Bruner's (1986) constructivist view, narratives play a key role in shaping human experience, for it is through narratives that we can integrate the new and unexpected into the socially intelligible, thus turning our experience into something meaningful that can be shared and communicated. Viewing bereavement in narrative terms implies considering the death of a loved one as a life event that profoundly shakes our self-narratives, a rupture that calls on us to "reconstruct a 
world of meaning that has been challenged by loss" (Neimeyer, Klass \& Dennis, 2014, p. 486). This narrative activity, into which we are launched, has two dimensions:

On the one hand, it entails a need to process the event story of the loss itself and its import for our lives, as we contend with questions about why it occurred and what it means for our lives going forward. On the other hand, it involves an attempt to access the back story of our relationship to the deceased, both to restore some sense of attachment security and reestablish a sense of continuity between the life we had and the life we face now (Neimeyer, Klass \& Dennis, 2014, p. 489, italics in original).

These two narrative dimensions of grief involve an effort after meaning, to use Bartlett's (1932) celebrated expression, on the part of the bereaved. According to Neimeyer, Klass \& Dennis (2014), the loss of a loved one typically gives way to a search for comprehensibility - whereby the bereaved tries to come to terms with the occurrence of the loss - and a search for significance, which involves assessing the impacts and consequential values of the loss. As a dynamic process that evolves over time, reconstructing meaning after a death ultimately results in personal changes, ranging from reconstructing the continuing bonds with the deceased (Neimeyer, Baldwin \& Gillies, 2006) to reorganising one's assumptive world or even reconstructing one's identity (Gillies \& Neimeyer, 2006). While self-narratives are crucial in accounting for these life changes, this reconstruction process in bereavement does not evolve exclusively within the individual sphere. Self-narratives and meaning-making are dialogically negotiated with other individuals in a larger cultural context characterised by certain dominant narratives of loss, endowed with specific tropes and themes, which can, in turn, be appropriated, reconstructed or resisted by the bereaved (Neimeyer, Klass \& Dennis, 2014).

The intrinsically dynamic aspect of bereavement brings to the fore the mediational role of narratives in providing a meaningful link between the past, the present and the imagined future. According to Bartlett's (1932) constructive approach on memory, people reconstruct and give sense to the past in light of the current situation and different possible futures (Wagoner, Brescó \& Awad, 2019). Applied to the bereavement process, this implies an ever-changing re-examination and reworking of self-narratives after the loss. It is precisely in this context of telling and re-telling these self-narratives that the addition of photographs can contribute to the meaning-making effort by 
providing contextual richness in triggering individual's unique memories and working them through by the visual storytelling (Kim, 2016).

\section{Using Photography as a Methodological Tool in Death-Related Loss}

The return to experience in psychology involves recognising the limitation of traditional mono-modal approaches based on verbal data, detached from context (Reavey, 2011). According to Reavey (2011), there is a growing acknowledgement that we do not experience the world through narrative alone, but also through embodiment and space, and that we use "multi-modal forms of expression and communication when (re)presenting these experiences in everyday life" (p. 5). This multi-modal approach to experience has brought with it a combination of verbal data, like interviews, together with visuals, such as video (see Brescó, Wagoner \& Herbig, 2020) or photography (Radley \& Taylor, 2003). As for the latter, there are different visual techniques. Photo elicitation is a well-established method in social science (Harper, 2002) that consists of inserting already existing images as an interview aid. Conversely, in participatory photography participants take their own photographs for a subsequent interview in order to bring about a richer account of their daily experiences, thus inviting the researcher to begin from the position of bearing witness to the participant's meaning-making process (Reavey, 2011). This approach, which endows participants with more agency in showing what is meaningful for them, can take the form of community-based participatory action research, as in the case of PhotoVoice methodology (Wang \& Burris, 1997), or a more individual-based form of photo self-elicitation (Harper, 2002). Though some of these visual techniques have been used in different studies of loss (Stutey, Helm, LoSasso \& Kreider, 2015), they have rarely been applied to the exploration of meaning-making processes within a therapeutic context (Arnold, 2018; Gamino, 2012).

At this point, it is important to distinguish between the role of photography as an object and its role as a process. In this respect, the focus here is not so much on the value already existing pictures may have for the bereaved as objects of the dead (Gibson, 2008), such as pictures of or owned by the deceased. The focus rather lies in the process embracing the very act of taking pictures on the part of the bereaved and the subsequent meaning-making processes these pictures can stimulate in the course of an interview or in a reflective exercise, such as expressive writing. That is why some researchers (Frith, 2011) use the term photo-production to emphasise the circumstances surrounding the moment when the pictures were produced, including the participants' intentions and reasons for taking them. While photographs in general can act as triggers for memory (Cronin \& Gale, 1996), 
there are substantial differences depending upon whether they are taken by the person being interviewed or by somebody else (Radley \& Taylor, 2003). Photo-production enables, on the one hand, situated memories of the moment in which the picture was taken to be brought into the future interview, where those memories will be triggered, talked about and (re)interpreted. On the other hand, photo-production also implies bringing the future into the very act of taking pictures and rendering them available for subsequent remembering, a decision dialogically taken vis-à-vis an anticipated and implicit interlocutor. As Cronin (1998) points out, "the act of photography anticipates the future by ripping the appearance of a moment out of its time, creating a tangible image for the future of what will be the past" (quoted in Radley \& Taylor, 2003, p. 131).

Including the context of production in the research process enables participants to reflect back on the moment when the picture was taken, and by doing so, make sense of the changes that have occurred since then; something crucial to the study of how bereavement evolves over time. In their study on patients' experiences during a hospital stay, Radley and Taylor (2003) found that in the interviews conducted at home, participants did not solely describe the pictures taken on the ward, nor did they limit themselves to recalling what happened back then. Most participants justified why they took the pictures in those circumstances in a narrative account characterised by a constant coming and going from the present to the past. In this process of exploring the link between past and present, the use of photography in interviews also helps to create more complex and layered narratives in which emotions and embodied states from the past, alongside the setting of the experience, are brought into sharper view (Reavey, 2011). In that respect, photographs become a tool to engage in meaning-making and visual storytelling, a technique whereby researchers and participants can jointly reflect on the multi-layered aspects of experience - situated in time and space - from a multi-modal approach, both narratively and visually.

\section{Using Photography as a Therapeutic Tool Following Death-Related Loss}

The use of expressive arts as therapeutic tools ${ }^{1}$ to facilitate people's expression of bereavement experiences has been gathering strength in recent years (Thompson \& Neimeyer, 2014). Among these varied artistic forms, visual arts, such as photography or painting, are increasingly frequent in grief therapy. In a recent review, Weiskittle and Gramling (2018) found that "grief interventions using visual art techniques facilitate continuing bonds and meaning making, but there is little evidence to

\footnotetext{
${ }^{1}$ See also Brinkmann et al. (2019) for arts-based research or the use of expressive arts as a possible methodological tool in the field.
} 
support a significant impact on negative grief symptomatology" (p. 21). According to these authors, these results seem to support the conceptualisation of grief as a multidimensional experience. In contrast with traditional approaches focused on grief as a one-dimensional experience of suffering, and consequently on alleviating the negative grief symptoms, reformulating bereavement as a complex system of experiences involves incorporating aspects such as meaning-making, continuing bonds, and purpose following loss. However, Weiskittle and Gramling (2018) are cautious in admitting that "we know very little of the processes by which visual arts facilitate continuing bonds and meaning making” (p. 21). Most of the reviewed studies were non-experimental, with no control group, based on subjective self-reports or clinician-rated judgments. Moreover, few of these studies specify the type of loss suffered by the participants. Lastly, the visual art techniques employed tend to play a secondary role, as they are often used as a complement to different types of therapy (Weiskittle \& Gramling, 2018).

Recent visual-based studies using photographs as therapeutic tools are opening up a promising way through which to develop new self-narratives (Strouse, 2014) and engage in sensemaking after loss (Renzenbrink, 2014). Drawing on a previous work by Creighton and colleagues (2013), Arnold (2018) explores the photographic narrative influence on how bereaved university students engage in meaning reconstruction following a death-related loss. Findings resulting from combining individual interviews with photographs taken by the participants in the study indicate that photo narrative facilitated meaning reconstruction in different ways. For instance, it facilitated the discovery of continuing bonds (Klass et al., 1996), thus allowing participants to reflect on their ongoing connections to their loved ones. It also facilitated sense-making (i.e., comprehending the loss) through different visual metaphors and insights regarding ways of making sense of the death and grief in terms of presence and absence. For example:

\footnotetext{
"Nature scenes depicted in photographs were often used to capture a way of making sense of life and death and the simultaneous presence of endings and beginnings. Images of bare trees in winter set against a vibrant blue sky, a flowing river amidst patches of ice, and a hazy sun shining through a grey sky helped to convey the delicate balance of living one's life amidst the pain and sadness of grief" (Arnold, 2018, p. 136).
} 
In sum, Arnold's (2018) findings seem to support the additional use of photographs as tools for reconstructing our self-narratives following a loss. Referring to Neimeyer's (2012) concepts of event story of the death and the back story of the relationship to the deceased, Arnold (2018) highlights how photographs acted as prompts that helped to bridge these two dimensions of the narrative by connecting the nature of the death and the relational bond through a meaningful reflection on the grief experience. If, according to Neimeyer, Klass and Dennis (2014), adaptive courses of grieving are associated with "the ability to scaffold a story that renders the loss comprehensible, and in some sense partially compensated by the life learning it entails" (p. 487), we may consider the use of photographs as therapeutic tools aimed at fostering this meaning-making process. This way, the work of grief can be expanded beyond the traditional mono-modal linguistic approach by allowing multi-modal forms through which one can better reflect upon an embodied and contextualised experience. Ultimately, photographs in this context could be regarded as mediational tools (Vygotsky, 1987) for meaning making, or even as a sort of technology of the self (Foucault, 1988) in that they can be purposively used by individuals to reflect and change their grief experiences.

\section{Case Study: Maria's Photo Project on Coping with Grief and Meaning-Making}

The following case study is based on Maria's (pseudonym) photographic project, which focuses on her way of coping and giving sense to her bereavement experience after the loss of Sofia (pseudonym), one of her best friends. By the time Maria starts the online university extension course, Photography as a therapy, run by the first author, ${ }^{2}$ she already knows that Sofia is dying, something that leads her to choose a photo project on the suffering generated by this situation. Let us remember that the course's main goal was to reflect on some of the current uses of photography as a possible therapeutic tool-viz., phototherapy and therapeutic photography. This one-month course embraced different activities, namely reading scientific articles, reflecting on various cases (such as that of Jo Spence, considered a pioneer in the use of photography as a therapeutic tool), discussion with the rest of the students in the virtual classroom and the preparation of various written projects. Among the latter, students had to hand in a final report with their personal photographic project, consisting of a set of pictures taken by the students themselves with respect to their daily life (optionally

\footnotetext{
${ }^{2}$ Aimed at updating knowledge in specific professional and educational fields, these online courses are offered by the Open University of Catalonia to the general public beyond the university community. In fact, Maria was not a university student; she saw the course advertised in the media and decided to register because the topic interested her.
} 
accompanied by written notes) and a reflection on the use of photography as a possible therapeutic tool.

The focus of this article lies in Maria's photographic project -included in the written report she handed in at the end of the course. In her case, Maria decided to combine the photographic exploration of her daily life with her bereavement process after losing her friend. Eight months after the end of the course, she was contacted again for an interview to discuss her photographic project and the development of her grieving process. However, due to space limitations, this will not be analysed in the present paper. At this point, it is worth noting that Maria-aged 34 when the project took place- is not a psychologist or photographer, although she does have training in audio-visual language.

\section{Maria's Project Overview}

Maria starts the course on therapeutic photography when her friend, Sofia, is hospitalised due to a very aggressive form of cancer. More specifically, Maria begins her photographic project the same day that Sofia's ashes are scattered, approximately a month and a half after the cancer was diagnosed. According to one of the available options offered within the course, Maria's project takes the form of a mini-documentary (an auto-ethnography) aimed at exploring her grief experiences at that time. Her report includes a series of photos, with some notes attached to them, as well as an interpretative analysis of these pictures and a critical reflection on the possible therapeutic utility of photography.

Drawing on the photo-production methodology discussed above, Maria would take between two and three photos a day for four days, setting alarms on her mobile phone to remind her to take them. The only explicit instruction given to her for this task was that she had to be aware of her feelings, emotions and thoughts at the very point at which she took the picture. In her report, Maria describes what this experience was like: "Every phone alarm reminds me that I have to stop, breathe, feel, observe, contemplate and decide" (Maria, 2019, p. 8). ${ }^{3}$ To the ten photos, most of them taken after hearing the alarm on her mobile, Maria would add a last photo in homage to Sofia, taken when she was still alive. This comes to a total of eleven photos included in Maria's final report. In addition, Maria would accompany each image with descriptive information (numbering of the photo, date and time, and a very descriptive title) and some notes written on the same day, thus building a kind of intimate diary, which prevalently offers a metaphorical interpretation of the image taken.

\footnotetext{
${ }^{3}$ All quotations -translated from the original Spanish - are reproduced with Maria's formal consent.
} 
Furthermore, in her report, Maria would order the photos chronologically, creating a visual narrative with a clear structure: beginning (photo 0), development (photos 1-9) and denouement (photo 10).

As for the main goal of the project, Maria wished to "process my suffering, understand my fears and blockages, heal painful emotions" (Maria, 2019, p. 1). She also stated that her project was about exploring:

“...life and death as two sides of the same coin. I want to reflect on these concepts as forming part of all the polarities with which I live, we all live. Contrasts and dualities that I often feel in conflict. I want to find a balance between these two extreme sides. I want to reflect on death, trying to break the taboo and the negative connotations that go with it" (Maria, 2019, p. 2).

In addition, at the beginning of her report, Maria pointed out that not only did this project coincide with the death of one of her best friends, but it also came about at a point when she had more time to educate herself and to reflect on her own life. Thus, the photographic project became a way for Maria to make sense of her grief experience and to explore her emotional reactions to something totally unexpected and painful, as well as an opportunity to gain better self-knowledge and to take care of herself.

\section{Analysis of Maria's Photographic Project}

Analysis of the photos taken by Maria ${ }^{4}$ will be presented in light of both their formal and content aspects. In following this analysis criterion, we sought to be faithful to Maria's own way of analysing her pictures in the project. She herself comments on her photographs by referring to aspects of "form" and "content". Along these lines, we also paid attention to the "materiality of the form" and the "interpretation of the content" analytical categories, borrowed from communication studies (Marzal, 2010). Regarding the formal aspects, we will focus on three points that Maria herself makes explicit in her work: the use of colour, preparation at the time of taking the picture and the composition of the pictures. With regard to the content, we will focus on an aspect discussed in Maria's project, namely whether or not people were present in the pictures. This aspect will be analysed vis-à-vis the above-

\footnotetext{
${ }^{4}$ We received Maria's consent to use the photographs in scientific publications, provided her face is not shown. To secure anonymity, we have added a black dot on those photos where her face appears.
} 
mentioned concepts of event story and back story (Neimeyer, Klass \& Dennis, 2014). This will allow us, in turn, to talk about other important aspects, such as Maria's meaning-making and grief coping strategies. Overall, despite the fact that the methodology draws broadly on semiotics, we are aware that our analysis -including the way in which visual and verbal narrative analyses are integrated - is influenced by Neimeyer's, Klass and Dennis (2014) theoretical framework.

\section{Formal aspects of the pictures}

Regarding colour, all the photos taken during the auto-ethnography are in black and white, except for one. Maria explains that she deliberately used black and white "to focus on content, shapes, lights and symbols rather than colour" (Maria, 2019, p. 2). By using black and white, she tries to express the feelings of "melancholy" and "calm" that were so pervasive during those days -she repeatedly refers to these feelings in her report, linking them with the tone and contrast of the black-and-white images. Of the eleven photographs included in her project, there is only one in colour: the one added at the end of the series in tribute to Sofia, a picture taken when her friend was still alive, before Maria commenced the photographic project (see photo 10 in Figure 2).

Regarding the time when the picture was taken, all the photographs, except for the first one (see photo 0 in Figure 1) and the final one (photo 10), are taken spontaneously right after hearing the alarms on her phone. Maria highlights this aspect in her report, thereby making explicit her intention of delimiting a project, covering the days after the loss of her friend, between two photos chosen by herself without the intervention of the alarm. As for the photo placed at the beginning (photo 0), it was taken on the very day on which Sofia's ashes were scattered - in a ceremony Sofia herself had planned. It accurately captures the moment of rest and self-care, after having accompanied her friend in her last days, a moment in which Maria is nonetheless thinking of Sofia and her absence. 


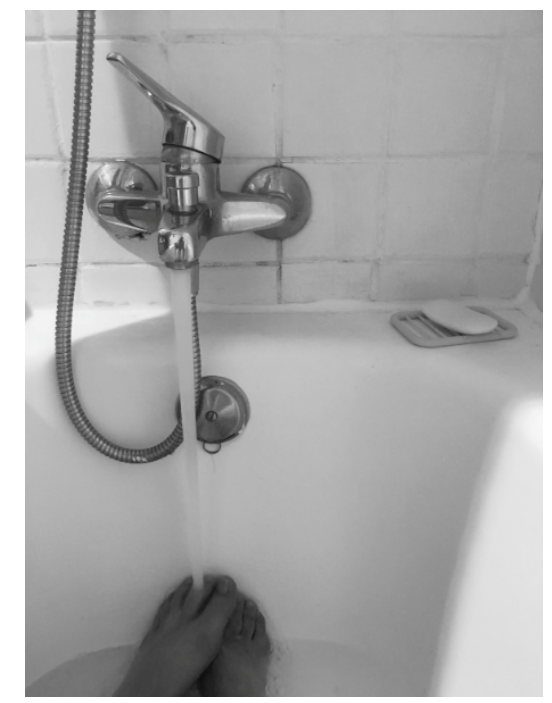

Figure 1. Photo 0: BATH. Wednesday 02.27.19 / 00:20

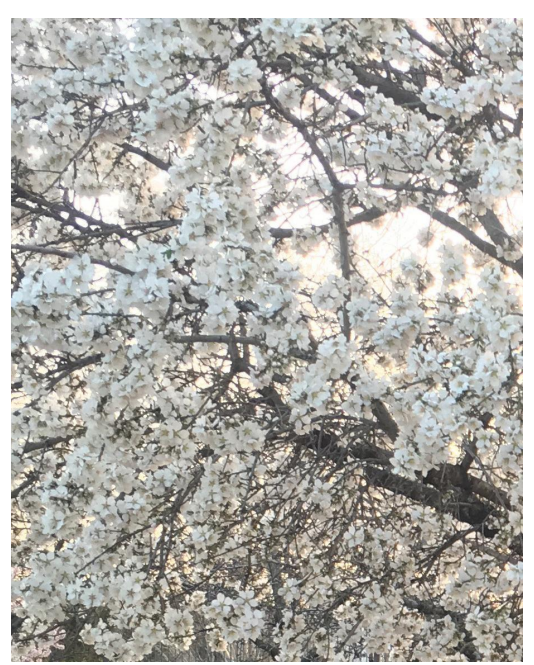

Figure 2. Photo 10: SOFIA

The image placed at the end (photo 10), entitled Sofia, is conceived as a clear tribute to her friend. It is the only picture not taken during the project's timeframe, that is, in the days after Sofia's death. It is a picture taken when Sofia was still alive in a special place for her - a garden in the centre of the city where she lived. In fact, it is the only photograph with no date or time. Maria deliberately concludes her project with this picture, thus breaking the "rules" of taking black-and-white photographs as part of an auto-ethnography of her daily life. Although Maria does not explain the metaphorical content of this image, various elements - viz., Maria's decision about the colour, the timing of the picture and the picture itself - show her intention of highlighting that, despite the 
suffering caused by the death of her friend, the memory of Sofia and her friendship remains, and will continue to remain, with her, bringing her joy.

Regarding the composition of the entire series of photos, Maria herself indicates that it is for the most part quite simple. More specifically, she points out: "as for the composition, I observe a trend towards the search for balance, with one part of the image sometimes having more strength than another" (Maria, 2019, p. 2). This search is, in fact, what Maria pursues through her project. In her own words, she seeks to "stay calm, in the balance between opposites, or not even opposites, but COMPLEMENTARY forces" (Maria, 2019, p. 3; capital letters in the original). As Maria herself highlights, these two complementary forces stand as a recurrent element in her self-portraits (see Figures 3 and 4).

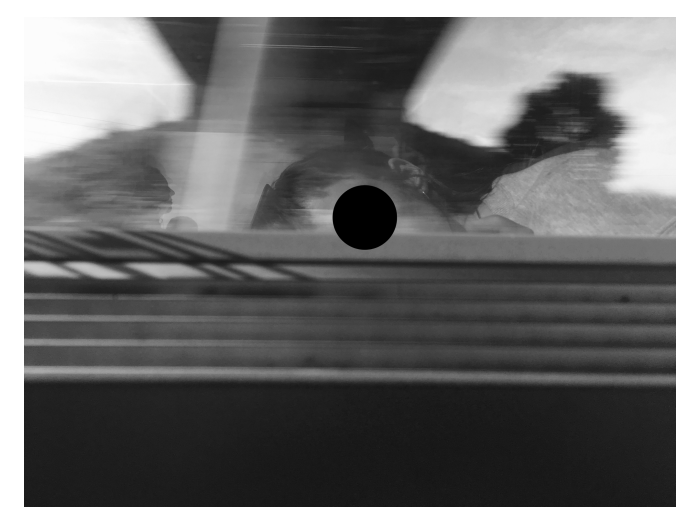

Figure 3. Photo 5: TRAIN. Thursday, 02.28.2019/ 16:25

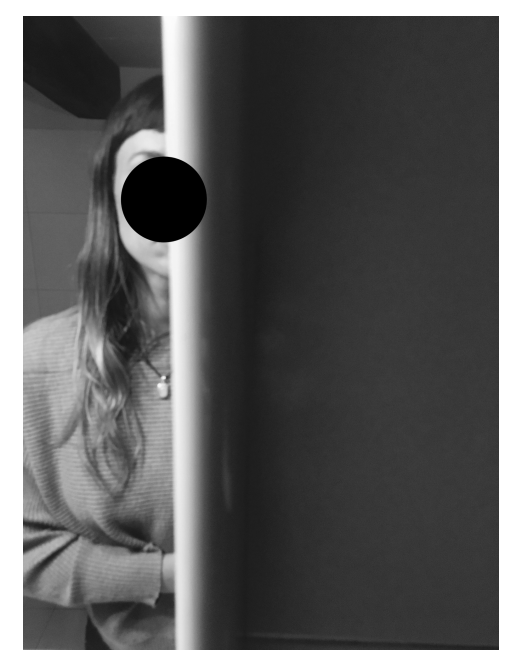

Figure 4. Photo 9: PORTRAIT. Saturday, 03.02.2019 / 00:25 


\section{Content aspects of the pictures}

Regarding the content, the photos tend to capture either everyday objects or images conveying parts of Maria's body. As for the former, Maria indicates in the notes attached to the pictures that all of the photographed objects turn out to have an important meaning for her, despite the fact that the photos were spontaneously taken upon hearing the alarm on the mobile phone. As for the latter, in four pictures we partially see Maria's face, her hands or her feet: "Through that human part, I include myself in the narrative, I fuse myself into the experience in a visual way, somehow I recognise myself and it brings me closer to the ideas that the image gives off" (Maria, 2019, p. 3). Often, these objects and body parts become photographic metaphors, helping Maria express her emotions and attribute meaning to what she experiences. Though analysed in more detail below, we can point to three clear examples of this in photo 1 (Figure 10), a picture of a window with curtains representing the separation between two worlds: life and death, photo 7 (Figure 5), showing a notebook representing a life that has to be written, and photo 8 (Figure 6), representing two spaces, surface and depth, in Maria's own words.

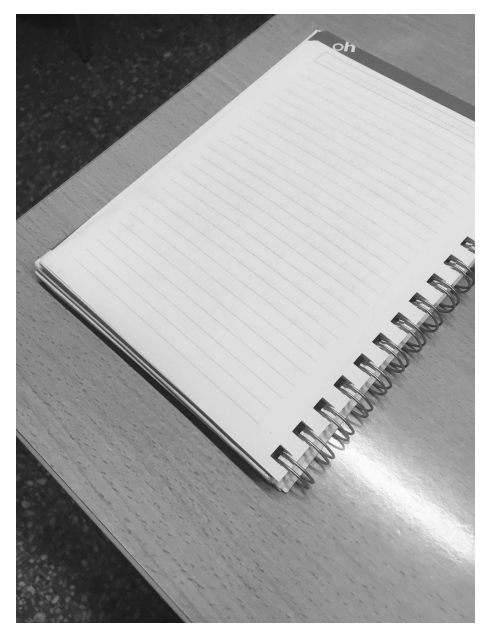

Figure 5. Photo 7: NOTEBOOK. Friday 03.01.2019/ 12:00 


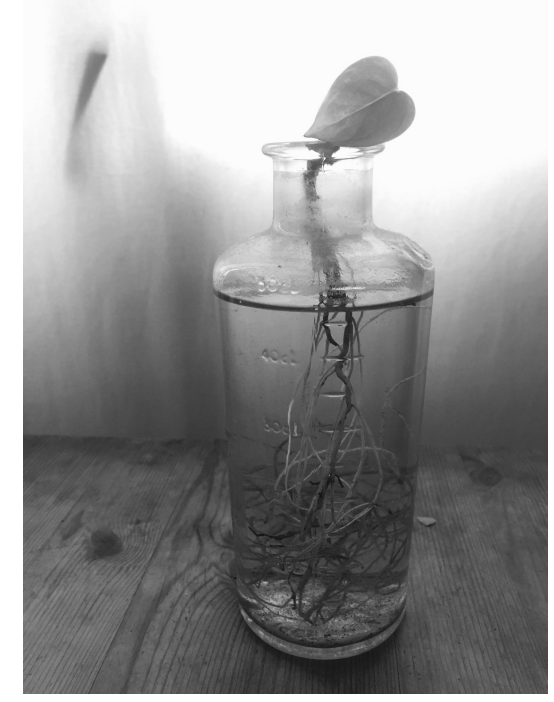

Figure 6. Photo 8: PLANT. Friday 03.01.2019 / 17:00

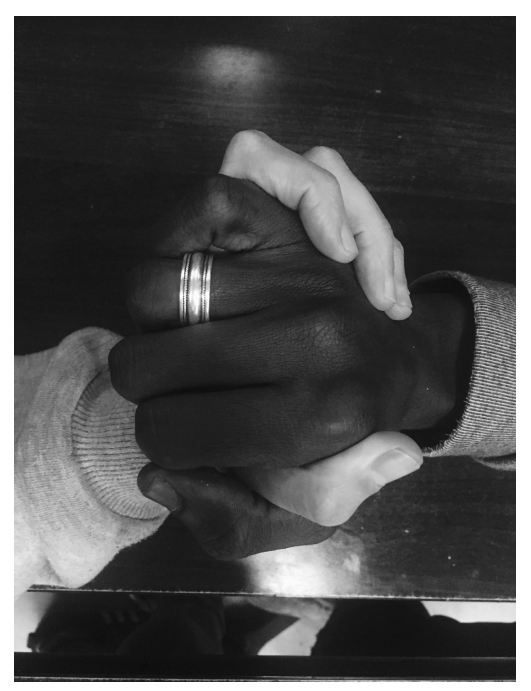

Figure 7. Photo 6: HANDS. Thursday 02.28.2019 / 23:00

At this point, it is worth noting that, although no other people appear in the pictures - except in photo 6 (Figure 7), where Maria's hand appears intertwined with her boyfriend's - half of them are taken at times when Maria is accompanied by people close to her. In fact, in her report the first person plural "we" appears as one of the most frequent words. Furthermore, in the notes accompanying half of the photos, there is always a direct reference to Sofia. Not only does her friend live on in Maria's memory, as photo 3 (Figure 8) poignantly shows, but Sofia seems to be present in a "spiritual" way for Maria, as if Sofia wanted to manifest herself from a place beyond death. This seems to be so, not only for Maria, but also for the rest of her friends, as shown in photo 3 (Figure 8). From the notes made after taking that photo, we infer that Maria is in a bar with some friends who were also friends of Sofia. In 
fact, in the moment the alarm goes off on her mobile, Maria is heading to the toilet, where the photo is taken. The picture shows a towel rack on which there is a sticker of a woman that says "no estáis solas", you (referring exclusively to women) are not alone. The impact of the loss of Sofia on Maria's friends is also expressed in photo 2 (Figure 9) where the six matches on the table represent the six friends that remained out of a group of seven following Sofia's departure.

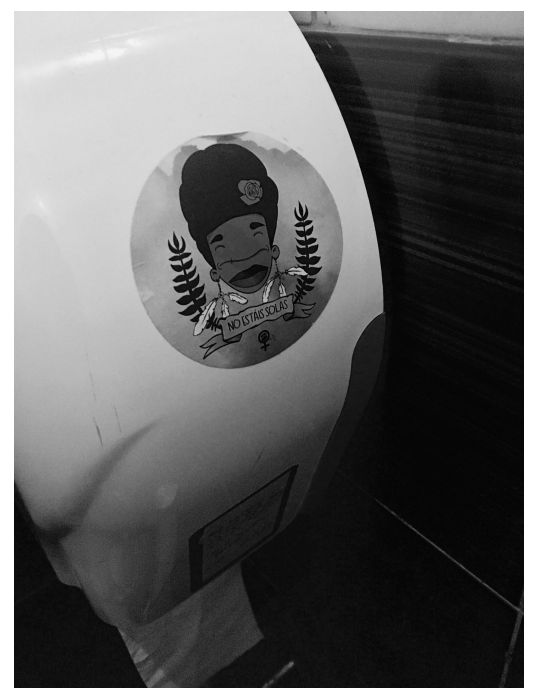

Figure 8. Photo 3: YOU ARE NOT ALONE. Wednesday 02.27.2019 / 21:10

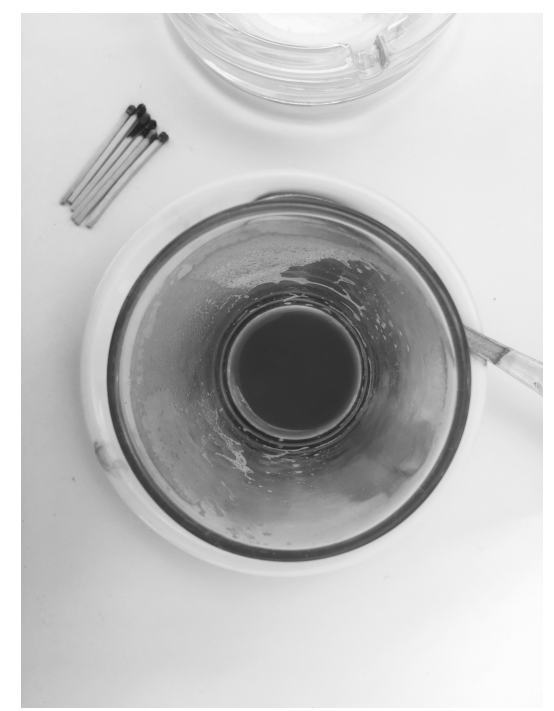

Figure 9. Photo 2: COFFEE. Wednesday 02.27.2019 / 16:45

The foregoing aspects allow us to delve into a more qualitative analysis, looking into the grieving narrative these pictures convey. On the one hand, we can identify how Maria tries to process and 
work through this narrative, the event story, that is, the loss of Sofia at the age of 34 due to a very aggressive form of cancer. In her effort to come to terms with this event -why it happened and what it means to her - the pictures Maria took scaffold various reflections. For instance, reflections on the expected course of life. Lives whose end is expected - like that of her grandmother, reflected in photo 4 (Figure 11) depicting the accordion of her great-grandfather - and other lives that should not end yet -as in Sofia's case, reflected in photo 10, a spring that comes "too soon" in Maria's own words. We also find reflections about the uncertainty of death and on what awaits us on the other side of life, like the curtains separating two spaces in photo 1 (Figure 10). Reflections on the place of death in life underlie several pictures, as in photo 7 (Figure 5) featuring an open notebook whose limited number of pages have yet to be written on. It is worth noting that this meaning-making effort is not confined within Maria's subjective sphere, as it takes place, dialogically, with those close to Maria. It takes place with Maria's father, who gave her Kübler-Ross' (1984) famous book, On Life after Death; with her friends, with whom she discusses what is happening to Sofia; with Sofia herself, with whom she exchanges concerns about the afterlife in the days before her death; with her partner, who comes from a different cultural and religious background, with different conceptions about death, bereavement, etc.

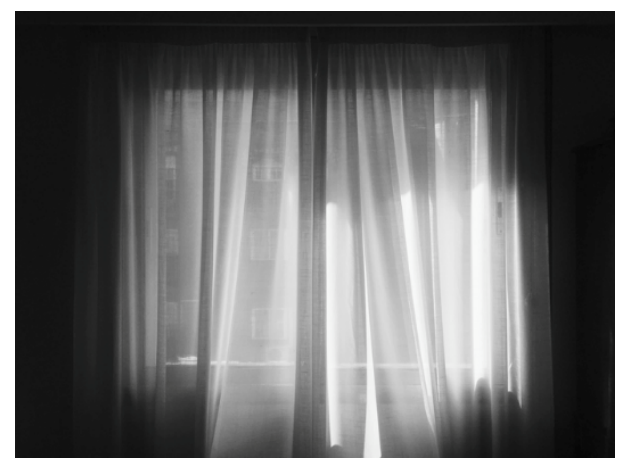

Figure 10. Photo 1: CURTAINS. Wednesday 02.27.2019 / 12:00

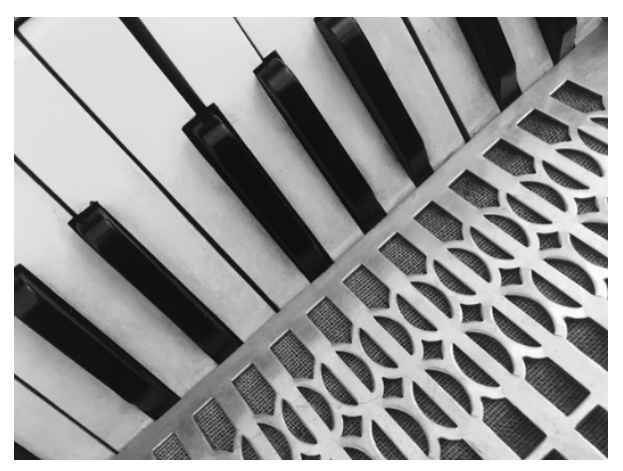


Figure 11. Photo 4: ACCORDION. Thursday 02.28.2019 / 11:00

On the other hand, Maria's grief narrative also reconstructs the back story, the meaning of the relationship with Sofia, with the aim of restoring the bond altered by death and re-establishing a certain sense of continuity between life with Sofia and life without her. Even if the group of friends has lost one of its members, Sofia is still present for each and every one of them, as shown in photo 3, with the message "you are not alone", as if Sofia were telling her friends that the connection with them is still alive. That affective bond with Sofia is also present in the form of different types of "legacies", as Maria herself put it, that Sofia seems to have passed on to her: the roller skates Sofia gave to Maria for her to fix them and start skating, and the "legacy" to break the taboo and talk more about death.

We can see clearly that, in the case of Maria, it is her spirituality, as well as the revision of her worldview to accommodate death, that allows her -even in those initial moments after losing her friend - to restore a certain coherence to a life altered by loss and to stay strong. Let us not forget that this is an anticipated grief and that Maria had actually been working through this loss prior to undertaking the photographic project. $^{5}$ Pictures also show very clearly how Maria's ability to maintain a sense of connection with her friend (continuing bonds) helps her cope with the loss, despite the traumatic circumstances of Sofia's death. As suggested by Neimeyer, Klass and Denis (2014), premature death is commonly associated with a greater search for meaning and is therefore accompanied by more intense and disabling grief symptoms (see also Payàs, 2017). Certainly, the way Sofia herself faced death and how she managed to live through her last few weeks (by talking calmly about what was happening to her, sharing moments with her loved ones, distributing belongings among them, etc.) also helped Maria to face loss with courage, while maintaining a strong connection with Sofia. Maria herself alludes to this aspect from the outset of her project: "A monster [cancer] that has been eating her from within, but one that [Sofia] has handled with serenity, setting an example for all of us who have been accompanying her in her final moments" (Maria, 2019, p. 1).

Along with this effort after meaning, evidenced in Maria's grief narrative, the photographic project also reflects her grief coping strategies. Most of Maria's reactions to Sofia's death lean towards the connection-approximation strategy (Payàs, 2017), that is, she allows herself

\footnotetext{
${ }^{5}$ Of course, this work does not end with the photographic project either. In a follow-up interview conducted months later -not included here due to space constraints- Maria showed how this meaning-making process has been evolving throughout that time.
} 
to express her emotions concerning loss instead of avoiding them. We can see this in photo 0 (Figure 1), featuring Maria taking a hot bath to rest and cleanse her weary body after accompanying Sofia in her last days, while recalling the scene of the scattering of her friend's ashes. It is also particularly evident in Maria's notes to most of her pictures, from which we know that most of the time she was in the company of those close to her -family and friends, including Sofia - with whom she allows herself to laugh and cry. Playing music to bear sadness (Figure 11) and reading about death as a way of coping with uncertainty - Maria's notes attached to photo 7 (Figure 5) mentioning Kübler-Ross' book - can also be interpreted as strategies along these lines. In addition to these coping strategies, there is another one, already present from the moment Sofia was diagnosed with cancer, but which became more and more evident with the passage of time: what Maria calls "breaking the taboo of death". Though the content of the interview - conducted nine months later - is not part of this article, what Maria seems to conclude at the end of it is quite revealing. According to her, the interview was a new opportunity to talk about what is never talked about, death, and perhaps a chance to give some kind of "meaning" or at least certain "purpose" to Sofia's painful loss. In short, Maria's meaningmaking and coping strategies lead her to at least try to take something positive from the loss of Sofia, to break the taboo of death, just as her friend had wanted. Here we can see the mediational role of the narrative allowing us to connect the past, present and future in a meaningful way.

Among Maria's meaning-making efforts and coping strategies, it seems reasonable to assume that the photographic project itself played a role in her grieving process, as a creative and occupational activity for self-empowerment (see Sitvast \& Abma, 2010; Thompson \& Neimeyer, 2014). Maria points out that the project gives her "strength and hope" at a time when she feels bad.

\footnotetext{
"Thinking about this experience, and reflecting on what I wanted to achieve by it, has already been a great motivation to carry it out. Thinking about my current suffering and embarking on a new experience with possible beneficial effects has given me strength and hope" (Maria, 2019, p. 7).
}

Beyond Maria's overall project, we can see each of the photographs contained in it acting as a mediational tool regulating Maria's emotions, or in Foucauldian terms, as a technology of the self aimed at transforming her emotions - generating calm - and helping her to better understand what she is experiencing. The act of photographing allows Maria to stop and pay attention to the emotion she is feeling at that precise moment. It is important to bear in mind that the project's goal was not limited 
to the role of photography as an object - for instance, in the form of a photo album or minidocumentary - but also to foster reflection on the processes surrounding the use of photography as a possible therapeutic tool. Photos help Maria to "externalise" what she feels, as if the photo were a physical materialisation of an internal emotional state. Through photography, Maria's emotions take on a material and concrete dimension in the form of an image that she, in turn, can visualise and (re)interpret, thus giving rise to further meaning-making processes. In addition to this, Maria puts the meanings associated with each picture on record by writing them down on a daily basis. This way, the written notes that accompany the images contribute, in turn, to Maria's emotional expression something underscored by Maria herself - and help her to work through the mourning experience -, since it is well known that writing is another therapeutic tool (Frisina, Borod \& Lepore, 2004). In sum, the act of taking a photo while paying attention to one's feelings at that specific moment and the contemplation of that image, along with its subsequent analysis in writing, becomes an exercise that helps Maria manage the negative symptoms of sadness, anger and uncertainty. Maria summarises this process in the following way:

\footnotetext{
“At first, I didn't really understand why, but when I started the project, I began to feel a sense of calm and some relief when taking the photographs (...). After the first day, my mind subconsciously started to feel that it was almost time for the phone alarm to go off and thus started working on a higher level of consciousness, stopping - depending on the situation I was in - to observe my surroundings and connect with my inner feelings. At times, I wanted to take more than one photo, but I decided to DECIDE and take only one. As the experience progressed, I began to realise that I was observing reality in a different way, looking for contrasts and harmony between them, accompanied by Sofia's presence" (Maria, 2019, p. 8; capital letters in the original).
}

Maria clearly points out two functions derived from the use of photography in her case: calmness and search for meaning. Two functions that derive, in turn, from the agentic role assumed by Maria throughout her project, as can be seen in the way she highlights the decisions she takes. Photography to some extent helps her to face the crisis of meaning (Neimeyer, Klass \& Dennis, 2014) generated by the loss of her friend and by the subsequent questioning of the meaning of life, as well as her own understanding of herself. In this context of rupture caused by Sofia's death it is not surprising that, 
throughout the written report, Maria talks openly about her values and her way of understanding relationships with others and of being in the world. Along these lines, there are constant references to feminism, the empowerment of women, multiculturalism and, in short, what she calls the need to integrate dichotomies: woman and man, white and black, life and death.

\section{Conclusions}

Through this case study, we aimed to show how photography, understood as both a process (as a project and act of photographing) and an object (the resulting picture), can be used as a means for meaning-making and the construction of narratives. In Maria's case, this has resulted in both visual narratives (supported by the temporal structure that Maria gives to her photographs) and verbal narratives (the notes accompanying the photos, as well as the overall report on the project). In this case, the use of photography and the resulting grieving narratives fulfil an inseparable double methodological and therapeutic function.

From a methodological point of view, the use of the photo-production technique allows attention to be focused on the contextual and emotional circumstances in which the photo was taken, as well as on the images themselves. This stimulates an effort to create meaning out of the experienced moment and to organise fragments of life into a coherent whole, thus connecting the past with the present and even with an imagined future. Photo-production facilitates the exploration of "embodied" emotions and reveals detailed information on the context from which narratives are generated. In Maria's case, for example, this has provided information on her coping strategies after loss. In addition, the use of photography contributes to the search for a coherent and understandable visual and verbal narration for both the participant and the implicit other - in this case, the online course teacher and Maria's fellow students. Both Maria's photographs and the notes accompanying them are taken from a dialogical perspective so that they can be shared and understood, in terms of both their content and their visual and verbal codes. Like Frith (2011), we believe that photographs not only function as "triggers" to facilitate memory but also as tools that scaffold and underpin certain narratives. Hence the practical impossibility of separately analysing the photographs and the notes attached to them, since, as some researchers point out (Radley, 2011), what is narrated is not really the content of the picture itself but the circumstances that led the person to take that picture in the first place. Finally, this methodology encourages participants to be agents of their own stories, choosing and deciding what and how they want to tell what happens to them. 
From a therapeutic perspective, photography helps the bereaved to work through the loss, enabling the construction of a narrative aimed at making sense of the grief experience, including the two dimensions indicated by Neimeyer, Klass and Dennis (2014). On the one hand, the event story, namely why it happened and what meaning the loss has for the bereaved, in this case for Maria. On the other hand, the back story, the meaning of the bond Maria maintains with Sofia and the need to restore a certain sense of continuity in a life shaken by loss. As already indicated, photographs -as objects resulting from Maria's project - contribute towards providing information about the context in which they were taken, and even to "stage" the moment in which Maria took the photo - photo as process. In our case study, the memories triggered by the pictures dragged up the emotions Maria was experiencing at the time of taking the photograph, thus resulting in a new opportunity for her to reinterpret those experiences and, by doing so, to connect the past with the present in a meaningful way. This process enables that moment to be felt again but in a different way, if we assume that remembering is a reconstructive and not merely reproductive act (Bartlett, 1932). The past is remembered not to suffer again, but to work through the emotions associated to one specific moment, to build a new narrative, a more complex and reflective one (Reavey, 2011). Once again, we see how the use of a multi-modal approach -visual and verbal- enables "embodied" emotions to be brought to the fore and worked through according to the individual's present needs. Furthermore, as we could see in Maria's case, photographs have fulfilled an emotional regulatory function by becoming tools used by Maria to remember, to connect with what she experienced at one particular moment and to externalise her experienced emotional state within the boundaries of a concrete picture. This "visualisation" and "materialisation" of internal emotions can be used as a means for self-regulation, hence the use of photography as a technology of the self (Foucault, 1988). Finally, it is worth noting that, while the use of photography did not occur in a therapeutic setting or with a therapeutic aim, Maria's voluntary decision to undertake a photographic project on her grief experience had a motivating function that helped her to cope with the pain generated by Sofia's loss.

Two points for critical reflection, regarding our analysis and the negative potential of photography as a tool for coping, are worth addressing before concluding. ${ }^{6}$ As for the former, while the paper has focused on Maria's project photographs, we cannot ignore the fact that our analysis takes place after interviewing this participant nine months following the online course. We are thus aware that the interview may have influenced our analysis of Maria's project. In fact, in the interview, Maria herself talks about what the experience of taking photos and writing about them during the

\footnotetext{
${ }^{6}$ We would like to thank the journal's reviewer for bringing these important points to our attention.
} 
course meant for her. That notwithstanding, the new narrative generated in the interview, which shows Maria's effort to make sense of what she experienced, far from weakening our conclusions, seems to reinforce the hypothesis of photography as a tool for creating meanings and exploring narratives of grief. As for the latter, one may wonder about the extent to which photography can contribute to "freezing moments" and whether it actually inhibits new ways of meaning-making. As far as our study is concerned, it is worth remembering that the course participants chose for themselves the project they wanted to work on. Thus, it could be expected that had there been students with grief avoidance/denial patterns, they would probably have refrained from addressing their grief experience as an object of study. Judging from Maria's experience, this was not the case. Despite the traumatic circumstances of Sofia's death, Maria seems to be in connection (Payàs, 2017) in that she is able to use coping strategies aimed at connecting with the reality of her friend's loss, for instance by establishing a "dialogue" with her through photography - along with other strategies such as sharing her emotions with others, reading about grief, writing, etc. More complicated cases would have required a psychological intervention whereby the support of an expert could help the subjects to work through the loss and the (new) meanings attributed to the photographs. In this regard, even if photographs "freeze" moments, we consider, as has been pointed out, that meanings can be dynamically constructed and reconstructed throughout time, whether in dialogue with oneself or with others.

In sum, we can conclude that photography is a tool that could serve a dual methodological and therapeutic purpose. We are aware that photography is a language that needs to be mastered - Maria had some knowledge of audio-visual communication - just like verbal language. Yet, more and more people are becoming increasingly competent in its use, as well as in the handling of new communication technologies. For this reason, in line with Reavey (2011), we believe that it is essential that researchers in psychology engage with these everyday forms of communication and expression. 


\section{Acknowledgements}

The authors are deeply grateful to Maria, whose generosity, reflections, courage and love for her friends made this work possible. The second author received financial support through the Culture of Grief Project, funded by the Obel Family Foundation.

\section{References}

Arnold, C. (2018). Using Photo Narrative to Explore Meaning Reconstruction among Bereaved University Students. Doctoral Thesis. Proquest.

Bartlett, F. C. (1932). Remembering: A Study in Experimental and Social Psychology. Cambridge University Press.

Brescó, I., Wagoner, B., \& Herbig, L. (2020). Memorials, movement and the method of subjective cameras: A multimodal study of person-environment interactions. The Qualitative Methods in Psychology Section Bulletin, 30, 7-17.

Brinkmann, S., Brescó, I., Kofod, E. H., Køster, A., Overvad, A., Petersen, A., Shur, A., Tateo, L., Wagoner, B. \& Winther-Lindqvist, D. A. (2019). The Presence of Grief: Research-Based Art and Arts-Based Research on Grief. Qualitative Inquiry, 25(9-10), 915-924.

Bruner, J. (1986). Actual Minds, Possible Worlds. Harvard University Press.

Creighton, G., Oliffe, JL., Butterwick, S., \& Saewyc, E. (2013). After the Death of a Friend: Young Men's Grief and Masculine Identities. Social Science and Medicine, 84, 35-43.

Cronin, O. (1998). Psychology and Photographic Theory. In J. Prosser (Ed.), Image-Based Research: A Sourcebook for Qualitative Researchers (pp. 69-83). Falmer Press.

Cronin, O., \& Gale, A. (1996). Photographs and the Therapeutic Process. Clinical Psychology Forum, 89, 24-28.

Foucault, M. (1988). Technologies of the Self. University of Massachusetts Press.

Frisina, P. G., Borod, J. C., Lepore, S. J. (2004). A Meta-Analysis of the Effects of Written Emotional Disclosure on the Health Outcomes of Clinical Populations'. Journal of Nervous and Mental Disease, 192, 629-634.

Frith, H. (2011). Narrating Biographical Disruption and Repair: Exploring the Place of Absent Images in Women's Experiences of Cancer and Chemotherapy. In P. Reavey (Ed.), Visual Methods in Psychology. Using and Interpreting Images in Qualitative Research (pp. 55-68). Taylor \& Francis. 
Gamino, L. A. (2012). Opening the Family Photo Album. In R. Neimeyer (Ed.), Techniques of Grief Therapy: Creative Practices for Counseling the Bereaved (pp. 231-233). Routledge.

Gibson, M. (2008). Objects of the Dead. Mourning and Memory in Everyday Life. Melbourne University Press.

Gillies, J., Neimeyer, R. A. (2006). Loss, Grief and the Search for Significance: Toward a Model of Meaning Reconstruction in Bereavement. Journal of Constructivist Psychology, 19, 31-65.

Harper, D. (2002). Talking About Pictures: A Case for Photo Elicitation. Visual Studies, 17(1), 1326.

Kim, J. (2016). Understanding Narrative Inquiry. Sage.

Klass, D., Silverman, P. R., \& Nickman, S. L. (Eds.) (1996). Continuing Bonds: New Understandings of Grief. Taylor \& Francis.

Kübler-Ross, E. (1991). On Life after Death. Celestial Arts.

Maria [pseudonym] (2019). Un Proyecto Personal en Marcha [A Personal Project Underway]. Unpublished work. Open University of Catalonia.

Marzal, J. (2010). Cómo se lee una fotografía. Interpretaciones de la mirada [How to read a photograph. Interpretations of the Gaze]. Cátedra.

Neimeyer, R. A. (2012). Retelling the Narrative of the Death. In B. E. Thompson \& R. A. Neimeyer (Eds.), Grief and the Expressive Arts. Practices for Creating Meaning (pp. 86-90). Routledge. Neimeyer, R.A., Baldwin, S.A., \& Gillies, J. (2006). Continuing Bonds and Reconstructing Meaning: Mitigating Complications in Bereavement. Death Studies, 30, 715-738.

Neimeyer, R., Klass, D., \& Dennis, M. R. (2014). A Social Constructionist Account of Grief: Loss and the Narration of Meaning. Death Studies, 38, 485-498.

Payàs, A. (2017). Las Tareas del Duelo [The tasks of Grief] ( $7^{\text {th }}$ Edition). Paidós.

Radley, A. \& Taylor, D. (2003) Remembering One's Stay in Hospital: a Study in Photography, Recovery and Forgetting. Health: An Interdisciplinary Journal for the Study of Health, Illness and Medicine, 7, 129-159.

Reavey, P. (2011). The Return to Experience: Psychology and the Visual. In P. Reavey (Ed.), Visual Methods in Psychology. Using and Interpreting Images in Qualitative Research (pp. 1-14). Taylor \& Francis.

Renzenbrink, I. (2014). Photographic Metaphor. In B. E. Thompson \& R. A. Neimeyer (Eds.), Grief and the Expressive Arts. Practices for Creating Meaning (pp. 198-201). Routledge. 
Sitvast, J. E., \& Abma, T. A. (2012). The Photo-Instrument as a Health Care Intervention. Health Care Analysis, 20(2), 177-195.

Strouse, S. (2014). Collage: Integrating the Torn Pieces. In B. E. Thompson \& R. A. Neimeyer (Eds.), Grief and the Expressive Arts. Practices for Creating Meaning (pp. 186-197). Routledge.

Stutey, D., Helm, H., LoSSasso, H., \& Kreider, H. (2015). Play Therapy and Photo-Elicitation: A Narrative Examination of Children's Grief. International Journal of Play Therapy, 25(3), 154-165.

Thompson, B. \& Neimeyer, R. (2014). Grief and the Expressive Arts. Practices for Creating Meaning. Routledge.

Vygotsky, L. (1987). The Collected Works of L.S. Vygotsky. Volume 4: The History of the Development of Higher Mental Functions. Plenum Press.

Wagoner, B., Brescó, I., \& Awad, S.H. (2019). Remembering as a Sociocultural Process. Springer. Weiskittle, R., \& Gramling, S. (2018). The Therapeutic Effectiveness of Using Visual Art Modalities with the Bereaved: a Systematic Review. Psychology Research and Behavior Management, $11,9-24$.

\section{About the Authors}

Belén Jiménez-Alsonso is Associate Lecturer at the Department of Psychology and Education, Universitat Oberta de Catalunya (Spain). She is also a clinical psychologist and Member of the Healthcare Professional Association La Providence in Toulouse (France). Her current research interests focus on grief from a psychological constructivist approach, specifically on how technologies (from photography to griefbots) mediate our mourning experience.

Ignacio Brescó De Luna is Associate Professor at the Department of Communication and Psychology, Aalborg University. He is member of the Niels Bohr Center for Cultural Psychology and the Culture of Grief Centre. His current research interests revolve around collective memory, the study of memorials and the study of grief from a psychological constructivist approach. 